\title{
Intensive Phase of Therapy of Tuberculosis and HIV Co-infection: CD4, CD8, and Certain Hematological Finding Amongst Patients in Yaounde Cameroon
}

\author{
Guiedem Elise $^{1,2, ~ *}$, Pefura Yone Eric Walter ${ }^{1,3}$, Ikomey George ${ }^{1,2}$, Gonsu Kamga Hortense ${ }^{1}$, \\ Monamele Chavely Gwladys ${ }^{1}$, Fokam Joseph ${ }^{1}$, Mesembe Martha ${ }^{2}$, Afane Ze Emmanuel ${ }^{3}$, \\ Okomo Assoumou Marie Claire ${ }^{1,2}$
}

\footnotetext{
${ }^{1}$ Faculty of Medicine and Biomedical Sciences, University of Yaounde I, Yaounde, Cameroon

${ }^{2}$ Center for the Study and Control of Communicable Diseases (CSCCD), Yaounde, Cameroon

${ }^{3}$ Pneumological Service, Yaounde Jamot Hospital, Yaounde, Cameroon
}

\section{Email address:}

guiedemelise86@yahoo.fr (G. Elise)

\section{To cite this article:}

Guiedem Elise, Pefura Yone Eric Walter, Ikomey George, Gonsu Kamga Hortense, Monamele Chavely Gwladys, Fokam Joseph, Mesembe Martha, Afane Ze Emmanuel, Okomo Assoumou Marie Claire. Intensive Phase of Therapy of Tuberculosis and HIV Co-infection: CD4, CD8, and Certain Hematological Finding Amongst Patients in Yaounde Cameroon. International Journal of Immunology. Vol. 3, No. 6, 2015, pp. 72-77. doi: 10.11648/j.iji.20150306.12

\begin{abstract}
Tuberculosis (TB) is an infectious disease which could cause depressive phenomena like those observed in Human Immunodeficiency Virus (HIV). Our study aimed at evaluating the changes of T-cells and certain blood parameters during intensive phase of TB treatment. In this prospective cohort, 140 consenting tuberculosis patients were enrolled. $5 \mathrm{ml}$ of blood was collected at baseline (M0), after one month (M1) and after two months (M2). Enumeration of CD4 cells, CD8 cells, and hematological parameters were done following standard protocols. The 118 participants comprised 63 (53.4\%) TB/HIV negative patients (group 1) and 55 (46.6\%) TB/HIV positive patients (group 2). At M0, blood levels of CD4, hemoglobin, total lymphocytes and platelets in group 2 were significantly lower than those of group 1 with $p$ values of $0.001,0.002,0.018$ and 0.032 respectively. CD8 level was significantly low in group 1 as compared to group 2 ( $\mathrm{p}$ value: 0.38 ). Monocytes were low in both groups with no significant difference (p value: 0.097). At M2, there was a significant increase in the levels of CD4, CD8, monocytes, and hemoglobin as compared to M0. There was no significant change on level of total lymphocytes and platelets. In group 2: At M2, there was a significant increase in the levels of CD4, monocytes, hemoglobin, and platelets, and no statistically significant change on levels of CD8 cells and total lymphocytes. TB infection may result in lymphopenia, monopenia, and anemia, while co-infection with HIV may add thrombopenia to the mentioned disorders.
\end{abstract}

Keywords: Anemia, HIV, Lymphopenia, Monopenia, Thrombopenia, Treatment, Tuberculosis

\section{Introduction}

Tuberculosis (TB) is an infectious disease which continues to cause high mortality and morbidity. According to the 2013 Worth Health Organization (WHO) report, over 9 million new cases have been recorded yearly with 1.5 million dead [1]. Co-infection with HIV is more worrying. From 1986, with the advent of HIV, there has been a resurgence of TB in the world. The role of HIV infection became very evident in this resurgence. WHO reported in 2013 an estimation of 360 000 TB patients co-infected with HIV [2]. In Cameroon, approximately $20-30 \%$ of TB patients co-infected with HIV die during the two months intensive phase of therapy [3]. The intensive phase of treatment of TB/HIV co-infected patients in Cameroon is carried out during hospitalization or through a weekly appointment under appropriate medical supervision. The classic therapeutic strategy of active TB is standardized and constituted of two phases: the two months intensive phase with an association of four drugs (rifampicin, isoniazide, ethambuthol and pyrazinamide) and the four months continuous has only two drugs (rifampicin and isoniazide). Antituberculosis treatment often leads to physiopathological effects which are mostly observed during the intensive phase $[3,4]$. These physiopathological 
manifestations are more frequent and severe in patients coinfected with HIV who receive both anti tuberculosis and antiretroviral therapy (ART) during the two first months of treatment [5, 6]. During HIV infection, virus replication causes the destruction of a large amount of CD4 T cells and monocytes. The persistence of viral replication strongly activates the immune system and induces a profound immunodeficiency of gradual apparition [7]. This strong activation of the immune system induces a significant increase in resting energy associated with a decrease in food intake that promotes anemia and causes a decrease in hemoglobin [8]. Immunosuppression related to virus replication favours the multiplication of mycobacteria and leads to tuberculosis [9].

Protective immunity to $\mathrm{TB}$ in humans relies upon monocytes and $\mathrm{T}$ lymphocytes that play a very important role in the control of infection. Tubercle bacilli are phagocytosed by alveolar macrophages within which they multiply. After phagocytosis of bacilli by macrophages, the bacilli's antigens are released and cause activation of non-specific $T$ lymphocytes to specific T lymphocytes CD4 and CD8. They secrete lymphokines that activate monocytes/macrophages and inhibit the growth of bacilli phagocytosed $[6,10]$. Their fundamental role in immunity against tuberculosis is confirmed by observations in patients infected with HIV with a CD4 lymphocytes count which gradually decreases and predisposes to the disease tuberculosis [10]. Antituberculosis immunity is primarily cell-mediated (lymphocytes, monocytes). Furthermore it has been shown that platelets are from inflammatory cells and are activated when they pass through the blood vessels [11]. The profile of CD4 cells, CD8 cells, total lymphocytes, monocytes, platelets and hemoglobin are not well elucidated during the intensive phase of treatment. Our study aimed at evaluating the changes of T-cells and certain blood parameter during the intensive phase of treatment at the Yaounde Jamot Hospital.

\section{Methods}

\subsection{Participants and Study Setting}

The recruitment of patient was undertaken at the main specialized tuberculosis centre at the Yaounde Jamot Hospital (YJH). As inclusion criteria, TB/HIV negative patients initiating anti $\mathrm{TB}$ treatment and $\mathrm{TB} / \mathrm{HIV}$ positive patients initiating anti $\mathrm{TB}+$ Anti Retroviral therapy (ART) were consecutively enrolled.

Among TB/HIV negative patients (group 1), 70 were eligible for the study; 63 remained in the study until M2 and 7 withdrew from the study.

Among TB/HIV positive patients (group 2), 70 patients were enrolled; 55 stayed in the study until the end, 3 stopped treatments, 5 died and 7 were overlooked between M0 and the M2. They were hospitalized during the intensive phase of treatment which lasts 2 months. This intensive phase of TB treatment in TB patients or in TB/HIV co-infected patients in Cameroon is carried out during hospitalization or through a weekly appointment under appropriate medical supervision. The classic therapeutic strategy of active tuberculosis is standardized and constitutes of two phases: the intensive phase has an association of four drugs (rifampicin, isoniazide, ethambuthol and pyrazinamide) and the continuous phase during four months has an association of only two drugs (rifampicin and isoniazide). The ART were constituted of three molecules (Zidovudine + Lamivudine + Efavirenz) or (Tenofovir + Lamivudine + Efavirenz).

\subsection{Material and Procedure}

TB patients were identified every day from the admission records of the hospitalization units of pulmonology services. Patients fulfilling the inclusion criteria gave their consent to participate in the study.

Demographics characteristics (age, gender) were collected. The diagnostic results were extracted from medical records. Various paramedical parameters were exploited for more information. The clinical state of participants was observed at baseline (M0), after one month (M1) and after two months (M2) of treatment. In this prospective cohort study, $5 \mathrm{ml}$ of venous blood was collected in EDTA tubes from each patient at M0, M1 and M2 using standard blood collection procedures. The samples were transported to the CSCCD laboratory of the Faculty of Medicine and Biomedical Sciences, University of Yaounde I where they were analyzed within $6 \mathrm{hrs}$ of collection. The enumeration of CD4 and CD8 cells was done using the FACSCount machine (Becton, Dickinson Belgium), hematological parameters (total lymphocytes, monocytes, platelets and hemoglobin) was measured using an automated (CELL-DYN 3200, Abbott France) and thin blood smear read by standard microscopy. All samples were analyzed strictly according to the manufacturer's guidelines.

\subsection{Ethical Considerations}

Ethical clearance for this study was obtained from the Cameroon National Ethics Committee $\left(\mathrm{N}^{\circ}\right.$ 237/CNE/SE/2012). Participation in this study was voluntary. A signed consent form was sought from all participants. Standard procedures were used and involved minimal risk to the participants. Study results were returned to the patients and incorporated into their medical records.

\subsection{Data Analysis}

Data collected during this study were entered into SPSS (Statistical Package for Social Sciences) version 15. Qualitative variables were represented as frequencies and proportions. Quantitative variables were presented as mean ( \pm standard deviation) when the distribution was considered normal, if not they were represented by their median (+ interquatile interval). Chi-square or Fischer test were used to compare proportions. Student T-test and its non parametric equivalent were used to compare means. For p-values below 0.05 , the difference was considered statistically significant with a confidence interval of $95 \%$. 


\section{Results}

\subsection{Participant's Characteristics (Table 1)}

Overall, 118 participants were recruited for the study: 66 $(50.9 \%)$ female and $52(49.1 \%)$ male. Participant's ages ranged from 18 to 70 years. They were distributed into two groups: group 1 consisted of $63 \mathrm{~TB} / \mathrm{HIV}$ negative patients with a median age of 27 years and the age range [2030 [ years being the most represented, whereas group 2 consisted of $55 \mathrm{~TB} / \mathrm{HIV}$ positive patients with a median age of 33 years and the most represented age group was [3040[ years. A statistically significant difference was noted between the two groups $(\mathrm{p}$-value $=0.003$ ). In group 1,35 $(56 \%)$ were female and $28(44 \%)$ were male while group 2 was made up of $31(56 \%)$ female and $24(44 \%)$ male. Both groups were comparable based on sex with a $\mathrm{p}$ value of 0.35 . Patients of both groups initiated anti TB treatment made up of rifampicin, isoniazide, ethambuthol and pyrazinamide. The group 2 patients in addition to anti TB initiated ART therapy; 53 patients initiating ART made up of Zidovudine $(\mathrm{AZT})+$ Lamuvudine $(3 \mathrm{TC})+$ Efavirenz (EFV) and 2 patients on ART comprised of Tenofovir (TDF) + Lamuvudine (3TC) + Efavirenz (EFV).

\subsection{Comparison Between Groups}

\subsubsection{Blood Parameters at MO (Table 1)}

At initiation (M0), mean $( \pm \mathrm{SD}) \mathrm{CD} 4$ count of group 1 patients was $537( \pm 36.3)$ versus $94( \pm 27.5)$ in group 2 with a significant $p$-value of 0.001 . Mean $( \pm \mathrm{SD}) \mathrm{CD} 8$ count of group 1 patients was significantly lower at $288( \pm 30.1)$ versus $430( \pm 80.9)$ in group $2(p$-value $=0.038)$. Mean $( \pm S D)$ monocyte was low in both groups and the difference was not significant $(p$-value $=0.097)$. Mean hemoglobin levels was higher in group 1 than group $2(\mathrm{p}$-value $=0.002)$. Mean platelet count was not significantly different $(p$-value $=0.32)$ in both groups.

Table 1. Intergroup comparison: demographics characteristics and mean parameters at baseline.

\begin{tabular}{|c|c|c|c|c|}
\hline & Parameters & TB/HIV- & TB/HIV+ & $\mathbf{P}$ \\
\hline \multirow{2}{*}{ Sex } & Female & $35(56 \%)$ & $31(56 \%)$ & \multirow{2}{*}{0.35} \\
\hline & male & $28(44 \%)$ & $24(44 \%)$ & \\
\hline Age & Mean age & 27 years & 33 years & 0.003 \\
\hline \multirow{7}{*}{$\begin{array}{l}\text { Mean }( \pm \mathrm{SD}) \\
\text { of blood } \\
\text { parameters }\end{array}$} & $\mathrm{CD} 4( \pm \mathrm{SD}) / \mathrm{mm}^{3}$ & $537 \pm 36.3$ & $94 \pm 27.5$ & 0.001 \\
\hline & $\mathrm{CD} 8( \pm \mathrm{SD}) / \mathrm{mm}^{3}$ & $288 \pm 30.1$ & $430 \pm 80.9$ & 0.038 \\
\hline & $\mathrm{CD} 8( \pm \mathrm{SD}) / \mathrm{CD} 8$ & $1.6 \pm 0.1$ & $0,2 \pm 0.06$ & 0.001 \\
\hline & $\begin{array}{l}\text { Total lymphocytes } \\
( \pm \mathrm{SD}) / \mathrm{mm}^{3}\end{array}$ & $1450 \pm 735$ & $1200 \pm 296$ & 0.018 \\
\hline & $\begin{array}{l}\text { Monocytes } \\
( \pm \mathrm{SD}) / \mathrm{mm}^{3}\end{array}$ & $125 \pm 21.5$ & $81 \pm 18.6$ & 0.097 \\
\hline & $\begin{array}{l}\text { Hemoglobin } \\
( \pm \mathrm{SD}) \mathrm{g} / \mathrm{dl}\end{array}$ & $10.5 \pm 0.3$ & $9.5 \pm 0.5$ & 0.002 \\
\hline & $\begin{array}{l}\text { Platelets ( } \pm \mathrm{SD}) \text {. } \\
10^{3} / \mathrm{mm}^{3}\end{array}$ & $351 \pm 21$ & $291 \pm 25$ & 0.032 \\
\hline
\end{tabular}

\subsubsection{Mean Increase of Blood Parameters at M1 and at M2} (Table 2)

After M2, CD4 cells increased faster in TB/HIV- patients by $+420 / \mathrm{mm} 3$ as compared to group 2 patients $(+209 / \mathrm{mm} 3)$, $\mathrm{p}$-value $=0.001 . \mathrm{CD} 8$ lymphocytes increased with the same rate in both groups, $\mathrm{p}$-value $=0.8$. Monocytes rose faster in TB/HIV- patients $(+459 / \mathrm{mm} 3)$ than in $\mathrm{TB} / \mathrm{HIV}+$ patients $(+200 / \mathrm{mm} 3)$ and the difference between both group was statistically significant ( $\mathrm{p}$-value $=0.001$ ). There was a decrease in hemoglobin levels at M1 which later increased; hemoglobin level increased faster in group 1 by $+2.7 \mathrm{~g} / \mathrm{dl}$ versus $+1 \mathrm{~g} / \mathrm{dl}$ in group 2 ( $\mathrm{p}$-value $=0.05)$. Platelet counts changed with the same rate in both groups, $\mathrm{p}$-value $=0.098$.

Table 2. Intergroup comparison: mean increase of blood parameters after two months of treatment.

\begin{tabular}{|c|c|c|c|c|c|c|}
\hline & \multicolumn{3}{|c|}{ Difference $\left(M_{1}-M_{0}\right)$} & \multicolumn{3}{|c|}{ Différence $\left(M_{2}-M_{0}\right)$} \\
\hline & TB/HIV- & TB/HIV+ & $\mathbf{P}$ & TB/HIV- & TB/HIV+ & $\mathbf{p}$ \\
\hline $\mathrm{CD} 4( \pm \mathrm{SD}) / \mathrm{mm}^{3}$ & $+189( \pm 143)$ & $+68( \pm 87)$ & 0.004 & $+420( \pm 299)$ & $+209( \pm 120)$ & 0.001 \\
\hline $\mathrm{CD} 8( \pm \mathrm{SD}) / \mathrm{mm}^{3}$ & $+57( \pm 58)$ & $+39( \pm 50)$ & 0.8 & $+124( \pm 106)$ & $+136( \pm 108)$ & 0,8 \\
\hline $\mathrm{CD} 4 / \mathrm{CD} 8$ & $+0.23( \pm 1)$ & $+0.6( \pm 0.2)$ & 0.2 & $0.23( \pm 1.00)$ & $0.06( \pm 0.32)$ & 0.8 \\
\hline T. Lymphocytes $( \pm \mathrm{SD}) / \mathrm{mm}^{3}$ & $+370( \pm 545)$ & $+100( \pm 105)$ & 0.004 & $+510( \pm 322)$ & $+460( \pm 374)$ & 0,6 \\
\hline Monocytes $( \pm \mathrm{SD}) / \mathrm{mm}^{3}$ & $+235( \pm 152)$ & $+137( \pm 144)$ & 0.9 & $+459( \pm 41)$ & $+200( \pm 84)$ & 0.001 \\
\hline Platelets $( \pm \mathrm{SD}) / \mathrm{mm}^{3}$ & $+1000( \pm 2379)$ & $+8000( \pm 3761)$ & 0.03 & $+16000( \pm 22679)$ & $+97000( \pm 48138)$ & 0.098 \\
\hline
\end{tabular}

\subsection{Comparing the Evolution of Biological Parameters Within Group. (Table 3)}

In group 1: After sixty days of follow-up the mean's variations were: CD4 cells $\left(537 \pm 36.3-957 \pm 50 / \mathrm{mm}^{3}\right), \mathrm{CD} 8$ cells $\left(288 \pm 30.1-412 \pm 103 / \mathrm{mm}^{3}\right)$, monocytes $(125 \pm 21.5-$ $\left.584.5 \pm 47.7 / \mathrm{mm}^{3}\right)$ and haemoglobin $(10.5 \pm 0.3-13.2 \pm 0.4 \mathrm{~g} / \mathrm{dl})$ with a significant p-value of $0.001,0.039,0.001$, and 0.001 respectively. There was no statistically significant change

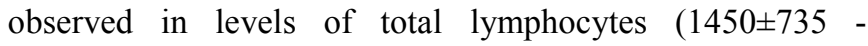
$\left.1960 \pm 105 / \mathrm{mm}^{3}\right)$ and platelets $(351000 \pm 21000$ -
$367000 \pm 17000 / \mathrm{mm}^{3}$ ) with $\mathrm{p}$-values of 0.097 and 0.7 respectively.

In group 2: After sixty days of follow-up, the mean's variations were: CD4 cells $\left(94 \pm 27.5 / \mathrm{mm}^{3}\right.$ $\left.303.5 \pm 38.5 / \mathrm{mm}^{3}\right)$, monocytes $\left(81 \pm 18.6\right.$ - $\left.281 \pm 78.8 / \mathrm{mm}^{3}\right)$, hemoglobin $(9.5 \pm 0.5-10 \pm 0.4 \mathrm{~g} / \mathrm{dl})$, platelets $(367,000 \pm 25910$

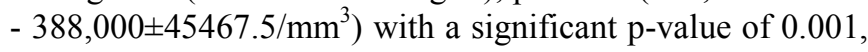
$0.001,0.001$, and 0.018 respectively. There was no statistically significant change of CD8 cells (430 \pm 80.9 $\left.566.5 \pm 79.4 / \mathrm{mm}^{3}\right)$ and total lymphocytes (1200 \pm 735.5 $1660 \pm 635 / \mathrm{mm}^{3}$ ) with p-values of 0.07 and 0.8 , respectively. 
Table 3. Intragroup comparison: Evolutionary changes from $M_{0}$ (initiation) to $M_{2}$ (60 days).

\begin{tabular}{|c|c|c|c|c|c|c|}
\hline \multirow[t]{2}{*}{ Parameters } & \multicolumn{3}{|c|}{ Tb/VIH- Group } & \multicolumn{3}{|c|}{ Tb/VIH+ Group } \\
\hline & $\mathbf{M}_{\mathbf{0}}$ & $\mathbf{M}_{2}$ & p & $\mathbf{M}_{\mathbf{0}}$ & $\mathbf{M}_{2}$ & $\mathbf{p}$ \\
\hline $\mathrm{CD} 4 / \mathrm{mm}^{3}$ & $537 \pm 36.3$ & $957 \pm 50$ & 0.001 & $94 \pm 27.5$ & $303.5 \pm 38.5$ & 0.001 \\
\hline $\mathrm{CD} 8 / \mathrm{mm}^{3}$ & $288 \pm 30.1$ & $412 \pm 103$ & 0.039 & $430 \pm 80.9$ & $566.5 \pm 79$ & 0.07 \\
\hline $\mathrm{CD} 4 / \mathrm{CD} 8$ & $1.6 \pm 0.1$ & $2.04 \pm 0.07$ & 0.001 & $0,2 \pm 0.06$ & $0.43 \pm 0.05$ & 0.02 \\
\hline T. Lymphocytes & $1450 \pm 735$ & $1960 \pm 105.5$ & 0.097 & $1200 \pm 296$ & $3710 \pm 1116$ & 0.8 \\
\hline Monocytes $/ \mathrm{mm}^{3}$ & $125 \pm 21.5$ & $584 \pm 47.7$ & 0.001 & $81 \pm 18.6$ & $281 \pm 78.8$ & 0.001 \\
\hline Platelets. $10^{3} / \mathrm{mm}^{3}$ & $351 \pm 21$ & $367 \pm 17$ & 0.7 & $291 \pm 25$ & $388 \pm 45$ & 0.018 \\
\hline
\end{tabular}

\section{Discussion}

The two groups were comparable with respect to sex; showing that both male and female has similar chances to contract TB or HIV. The [30-40[years age group was the most represented in TB/HIV co-infected patients suggesting that this age rang is the most sexually active in Cameroon.

Commonly, TB infection is controlled by adaptative immune system involving CD4 T cells in healthy persons (but does not eradicate) $[13,14]$. Decrease in CD4 T-cells count in TB/HIV- patients could be explained by the fact that MTB infection is a chronic infection in which attraction of CD4 lymphocytes in peripheral blood is intense during a long period and thus leads to the reduction in their levels in the blood. Immune failure to the defence processes results in clinical TB. TB infection can thus cause CD4 lymphopenia similar to that observed in HIV, but however, will not inverse the CD4/CD8 ratio as in HIV. This depletion is shown by the increases of CD4 during TB treatment. The increase was faster in TB/HIV-patients than in $\mathrm{TB} / \mathrm{HIV}+$ patients due to the persistence of HIV replication despite ART therapy [15] while anti TB treatment kills Mycobacterium progressively [16]. This is certainly why CD4 lymphopenia is less pronounced in group 1 as compared to group 2. These results allow us to suggest that $\mathrm{CD} 4$ depletion due to $\mathrm{TB}$ can be significantly recovered in two months of intensive treatment of TB.

An increase in the level of CD8 at M2 in group 1 suggests that MTB infection causes a decline in this cell. CD8 T cells have at least two major functions in control of MTB infection: the first function is cytotoxic activity, which can result in intracellular bacterial killing as well as killing of the infected macrophage; and second function is cytokine production which attracts macrophages and forms granuloma to fight against infection [18]. Lower CD8 cells in the peripheral blood may be related to the formation of this granuloma which attracts cells involved in infection control such as CD8.

During HIV infection, T helper cells constantly stimulate the proliferation of CD8 T cells which is intensified during viral replication. This replication is related to an accumulation of CD8 T cells memory and this then explains its high rate in peripheral blood in $\mathrm{TB} / \mathrm{HIV}+$ group.
There was an increase in the levels of total lymphocytes in both groups though not statistically significant. This could be attributed to an increase in CD4 and CD8 T-cells during treatment.

Monocytes were very low in both groups at baseline without a significant difference between them when compared to M2. This can be explained by the fact that TB granuloma attracts monocytes from the blood [20, 21], thereby reducing their levels. At M2, Monocytes increased at a mean level of 424 cells $/ \mathrm{mm}^{3}$ in TB/HIV-patients while an increase of 200 cells $/ \mathrm{mm}^{3}$ was observed in TB/HIV+ patients. This can be due to the fact that monocytes are also targets to HIV [22, 23].

Hemoglobin level decreased in TB/HIV+ patients during the first month and later increased during second month. ART like AZT, 3TC, and TDF are reverse transcriptase inhibitors (RTINs) acting on the reverse transcriptase becoming both substrate and inhibitors of reverse transcriptase and thus block the elongation of the viral genome. RTNIs have myelossupressor effect in general, particularly AZT which has the property to inhibit erythrocyte production [24, 25]. In most cases moderate macrocytic anemia is observed early in treatment [26]. This anemia is monitored by early medical surveillance and prevents the installation of profound anemia. Moreover, anemia may also be associated with strong activation of immunity due to viral replication inducing a significant increase in resting energy associated with a decrease in food intake thus promoting anemia and decreasing hemoglobin levels [8]. However, the significant increase of hemoglobin level after two months of treatment suggests that infections by MTB induces anemia in patients. These results can be explained by two facts: the hyper secretion of inflammatory cytokines (IL-1, TNF, IFNy) during TB inhibit the growth of erythroid progenitors and disrupt the synthesis of erythropoietin. The 2 nd point is the poor mobilization of iron for erythropoiesis du to its sequestration by macrophages (involved in phagocytosis) which causes a decrease in release of iron for the erythroblasts; the stock of available iron for erythropoiesis becomes insufficient causing anemia [10]. Kawai et al., in Tanzania also found anemia in patients with tuberculosis regardless of their status [27] and attributed it to malnutrition associated to TB infection.

Concerning platelet levels, there was no significant change 
in TB/HIV - patients while a statistically significant increase was observed in $\mathrm{TB} / \mathrm{HIV}+$ patients at $\mathrm{M} 2$, suggesting that $\mathrm{TB}$ itself is not lead to thrombopenia. During HIV infection, there is a cross immunity between HIV and platelet glycoproteins leads to peripheral immune destruction similar to that of autoimmune thrombocytopenic purpura. This may be the reason why platelet count is decreased at baseline in $\mathrm{TB} / \mathrm{HIV}+$ group compared to two months following ART therapy [28]. Similar results were reported by Nardi et al. where an increase in platelet count of HIV positive patients was observed after administration of AZT therapy [29].

The main strength of this study is the fact that it was carried in a resources limited setting in which the prevalence of TB and HIV co-infection is high and very limited studies have been carried out during these phase of treatment. We did not measure the macrophages level which is a limitation to the study.

\section{Conclusion}

We therefore conclude that tuberculosis itself could be associated with lymphopenia, monocytopenia and anemia, while co-infection with HIV may add thrombopenia to the mentioned disorders. The post intensive TB treatment showed the tendency of these depletions of recovery to normal.

\section{References}

[1] WHO. Global tuberculosis report, 2013.

[2] WHO. Global Report. UNAIDS report on the global AIDS epidemic, 2013.

[3] Kuaban C., Pefura E, Bava D, Onana I. Early mortality in new patients on treatment for smear positive pulmonary tuberculosis in Yaounde-Cameroon. Health Sci. Dis: (December 2011). Vol 12 (4).

[4] Mvondo D. La nutrition, traitement adjuvant du syndrome d'immunodéficience acquise (SIDA), 2000. www.supersmart.com/nutranews

[5] Dagara A.Y., Adjih K., Tchaptchet Heunda S. Prévalence de la co-infection VIH-tuberculose et impact de l'évolution VIH sur la tuberculose pulmonaire au Togo. Bull. Soc. Pathol. Exot., 2011,104, 342-346.

[6] Ait-Khaled N, Enarson D. Tuberculose Manuel pour les Etudiants en Medecine. Who/CDS/TB/99.272.

[7] Afane Ze E. , Guiedem E., Okomo Assoumou MC, Pefura Yone EW. Impact Dépressif de l'Infection Tuberculeuse sur les Cellules Immunitaires de Défense. 2013; Health Sci. Dis: Vol 14 (2).

[8] Semba RD, Tang AM. Micronutrients and the Pathogenesis of Human Immunodeficiency Virus Infection., Br J Nutr, 1999; 81: 181-189.

[9] Aska A., Anazi A., Subaei A., Hedaithy M. CD4+ Tlymphopenia in HIV negative tuberculous patients at King Khalid University Hospital in Riyadh, Saudi Arabia. 2011, jun 21 16(6): 285-8.
[10] Aubry P. La tuberculose à l'heure du SIDA, actualités. 2011; Medecinetropicale.free.fr/cours/tuberculose-sida.pdf

[11] Coussens K., Wilkinson J., Vladyslav N, Elkington T., Yasmeen H, Kamrul I, Peter M., Graham H. B., Alleyna P., Geoffrey E., Mathina D, Heather J., Baker V,. Barker D., Drobniewski A., Mein A., Leena B., Nuamah A., Griffiths J., Martineau R. Ethnic Variation in Inflammatory Profile in Tuberculosis. Published. 2013; DOI: 10.1371/journal. ppat. 1003468 .

[12] Davoudi Rasoolinegad M, younesian M, Hajiabdolbaghi M, soudbakhsh a, Jafari s, Emadikouchak H, Mehrpouya M, Lotfi H. CD4+ cell counts in patients with different clinical manifestations of tuberculosis. 2008; Braz J Infect Dis; 12: 483-6.

[13] Aït-Khaled N, Alarcón E, Armengol R: Prise en charge de la tuberculose. Guide des éléments essentiels pour une bonne pratique. (Sixième édition). Union Internationale Contre la Tuberculose et les Maladies Respiratorires. 2010.

[14] Uppal S. Tewari C., Verma S., Dhot P. Comparison of CD4 and CD8 Lymphocyte Counts in HIV-negative Pulmonary $\mathrm{Tb}$ Patients with Those in normal blood Donors and the Effect of antitubercular Treatment: Hospitalbased Flow Cytometric study. Cytometry Part b (Clinical Cytometry). 2004; 61b: 20-6.

[15] Bonaparte M.I., Barker E., killing of human immunodeficiency virus infected primary T-cell blasts by autologous natural killer cells is dependent on the ability of the virus to alter the expression of major histocompatibility complex class I molecules. Blood. 2004; 104: 2087-2094.

[16] Afane Ze A, Bitchong C E, Pefura Y E. Co-infection tuberculose et VIH: hausse des CD4 avec le traitement par antituberculeux seuls. Revue de médecine et de pharmacie $\mathrm{N}^{\circ} 1$ 2011: P 75-82.

[17] Dinh A., Perronne C. Aspects cliniques et thérapeutiques de la tuberculose chez l'adulte et l'enfant. EMC-Maladies infectieuses. 2013; 10(4): 1-11[article 8-038-C-30].

[18] Dhruv S., Carolyn Bigbee, JoAnne L. Flynn and Denise E. contribution of CD8+ T Cells to Control of Mycobacterium tuberculosis Infection. J Immunol 2006; 176:4296-4314.

[19] Leclercq p., Roudière L., Viard J.P. severe complicatins of antiretroviral treatments. Reanimation 13. 2004, 238-248.

[20] Stephen H.-F. M. Elliott W., Coleman M., Dorris E. R., Parthiban N., Wui-Mei Chew, McLaughlin A.M., Keane J. Networked T Cell Death following Macrophage Infection by Mycobacterium tuberculosis. PLoS One. 2012; 7(6): e38488.

[21] Lang P.A., Lang K.S., Xu H.C., (2011). Natural killer cell activation enhances immune pathology and promotes chronic infection by limiting CD8+ T-cell immunity. Proc Natl Academie des Sciences USA.

[22] Joshua S. Woodworth, Ying $\mathrm{Wu}$ and Samuel M. Behar. Mycobacterium tuberculosis-Specific CD8_ T Cells Require Perforin to Kill Target Cells and Provide Protection In Vivo. $J$ Immunol 2008; 181:8595-8603.

[23] Sarah M. Alejandra S. Mycobacterium tuberculosis Inhibits Macrophage Responses to IFN- $\mathrm{Y}$ through Myeloid Differentiation Factor 88-Dependent and -Independent Mechanisms. J. Immunol. 2004 172:6272-6280. 
[24] Pharmaetudes. antirétroviraux; version 2,5. de www.pharmaetude.com de www.pharmaetude.com

[25] Khalid S., Mustapha M., Ibrahim H., Andes E. Cytopenie et virus d'immunodeficience humaine. Doi: 10 1684/met 2011, 17 (3) 183-195.

[26] Török M.E., Farrar J.J. When to start antiretroviral therapy in HIV-associated tuberculosis. N. Engl. J. Med., 2011, 365, 1538-1540.

[27] Kawai K., Villamor E., Mugusi F., Saathoff E., Urassa W.,
Bosch R., Spiegelman D., Predictors of change in nutritional and hemoglobin status among adults treated for tuberculosis in Tanzania. 2011; 15(10): 1380-1389.

[28] Yonghong F., Hongyun Y., Guangliang M., Mao L, Yue J, Xiao H, Zhongyi H. Elevated Serum Levels of CCL17 Correlate with Increased Peripheral Blood Platelet Count in Patients with Active Tuberculosis in China. 2011; 18(4): 629632.

[29] Nardi MA, Li Z, Karpatkin S. HIV-1-related thrombocytopenia. In: Platelets (Second Edition): 847-59. 